\title{
Evaluation of olopatadine $0.2 \%$ in the complete prevention of ocular itching in the conjunctival allergen challenge model
}

This article was published in the following Dove Press journal:

Clinical Optometry

28 July $201 \mathrm{I}$

Number of times this article has been viewed

\section{Alan G Kabat' \\ David B Granet ${ }^{2}$ \\ Dina Amin ${ }^{3}$ \\ Maria J Tort ${ }^{3}$ \\ Michael S Blaiss ${ }^{4}$}

'Nova Southeastern University, Fort Lauderdale, FL, USA; ${ }^{2}$ Shiley Eye Center, University of California San Diego, La Jolla, CA, USA; ${ }^{3}$ Alcon Research Ltd, Fort Worth, TX, USA; ${ }^{4}$ University of Tennessee Health Science Center, Memphis, TN, USA
Correspondence: Alan G Kabat

Nova Southeastern University,

3200 South University Dr,

Fort Lauderdale, FL 33328-2018, USA

$\mathrm{Tel}+\mathrm{I} 954262$ I440

Email kabat@nova.edu
Background: Olopatadine hydrochloride ophthalmic solution $0.2 \%$ (PATADAYTM; Alcon, Fort Worth, TX) (olopatadine $0.2 \%$ ) is a formulation of a multi-action agent that has been approved for the treatment of ocular itching associated with allergic conjunctivitis when used once daily.

Objective: To evaluate olopatadine $0.2 \%$ versus its vehicle in the complete prevention of ocular itching in adult patients with allergic conjunctivitis.

Methods: This paper presents a post-hoc analysis of subgroup results from a single-center, double-masked, randomized, contralateral eye, conjunctival allergen challenge study. The posthoc efficacy analysis, conducted with data from patients who instilled olopatadine $0.2 \%$ in a single eye and vehicle in the contralateral eye, compared the ability of each study formulation to completely prevent ocular itching at three assessment time points post-instillation. Safety was not reevaluated in the post-hoc analysis.

Results: Overall, 40 patients received contralateral instillations of study drug and were included in the post-hoc analysis. At all three post-instillation time points, significantly greater proportions of patients reported itching scores of 0 in the olopatadine $0.2 \%$-treated eye than in the vehicle-treated eye (63\%-65\% versus 3\%-10\%, respectively; $P<0.05$ for each comparison). Within the previously reported results for the full study, no clinically relevant or statistically significant changes from baseline were observed for patients in regard to visual acuity, ocular signs, or fundus parameters.

Conclusion: Olopatadine $0.2 \%$ is safe, well tolerated, and superior to vehicle in completely preventing ocular itching that results from allergen exposure following drug instillation in patients with allergic conjunctivitis.

Keywords: allergic conjunctivitis, zero-itch, efficacy, safety, CAC

\section{Introduction}

It has been estimated that approximately 120 million people in the United States suffer from ocular allergies, and over $95 \%$ of these individuals are diagnosed with seasonal or perennial allergic conjunctivitis. ${ }^{1,2}$ Allergic conjunctivitis occurs due to a type-I hypersensitivity cascade reaction triggered by allergen-mediated cross-linking of immunoglobulin E ( $\mathrm{IgE}$ ) molecules on the conjunctival mast cell surface and the subsequent release of immunologic mediators, including histamine and inflammatory and vasoactive cytokines and chemokines from conjunctival mast cells and epithelial cells. ${ }^{3}$ The early phase of the ocular allergic response is mediated primarily by histamine through interaction with $\mathrm{H} 1$ receptors, which induces the classic signs and symptoms of the ocular allergic response, including ocular itching. ${ }^{4}$ Late-phase 
events, which prolong the allergic response, are mediated by the histamine-induced release of numerous intermediates, including tumor necrosis factor-alpha (TNF- $\alpha$ ), interleukins, monocyte chemoattractant protein (MCP)-1, eotaxin-1, and intercellular adhesion molecule (ICAM)-1 from conjunctival mast cells and epithelial cells, as well as from the infiltration of the ocular mucosa with inflammatory cells (eg, lymphocytes, basophils, neutrophils, and eosinophils). ${ }^{3,5,6}$

Multi-action compounds that affect several intermediaries of the allergic response have been developed for the treatment of ocular allergies. In particular, olopatadine hydrochloride ophthalmic solution, $0.2 \%$ (olopatadine $0.2 \%$ ) (PATADAYTM; Alcon, Fort Worth, TX), is a multi-action, topical ocular agent that has been shown to: block histamine receptors (with an especially high affinity for $\mathrm{H} 1$ receptors); inhibit mast cell degranulation, vasodilation, and vascular permeability; and diminish allergic inflammatory effects by inhibiting the recruitment and activation of eosinophils and other immune cells. ${ }^{4}$ Olopatadine $0.2 \%$, which is approved for the treatment of ocular itching associated with allergic conjunctivitis, ${ }^{7}$ has been shown to have superior $\mathrm{H} 1$ receptorselectivity relative to other ophthalmic anti-allergy drugs such as levocabastine, pheniramine, and antazoline. ${ }^{8}$

While ocular itching is a cardinal symptom of allergic conjunctivitis, it is also a common symptom that may be consistent with other ocular disorders such as contact dermatitis and blepharitis. ${ }^{9-11}$ Interestingly, in the treatment of this medical condition, patients actually have the choice of using a placebo vehicle (ie, an artificial tear) or an active medication. Since washing away an allergen is expected to have a mild impact on the disease, artificial tears are not a true placebo, but rather a vehicle control. Because the presentations of these disorders often overlap, patients may choose to self administer over-the-counter artificial tear preparations, which would be far less effective in treating allergic conjunctivitis symptoms. Even when used in an attempt to treat ocular itching associated solely with allergic conjunctivitis, patients are likely to be unaware that there are substantial differences in both mechanism of action and efficacy between artificial tear products, which simply just wash an allergen temporarily from the eye, and multi-action compounds, which effectively and safely treat the symptoms resulting from an allergic reaction. Previously reported studies conducted with multi-action compounds have primarily focused on evaluations of safety and efficacy (both at onset and duration of action). Since patients would be expected to choose between over-the-counter artificial tear preparations and multi-action prescriptive compounds, it is especially important in regard to patient education to evaluate a multi-action compound's ability to completely prevent ocular itching associated with allergic conjunctivitis.

The conjunctival allergen challenge (CAC) model has frequently been used in clinical studies designed to evaluate topical ocular antihistamines. In this model, ocular allergies are induced and evaluated in a consistently controlled manner in which both the onset and duration of action for a specific test article can be compared with either a vehicle or other topical treatments. ${ }^{12}$ The CAC model has specifically been used to evaluate the efficacy of olopatadine $0.2 \%$ in regard to the reduction of ocular itching for up to 24 hours after topical ocular administration. ${ }^{13}$

In order to evaluate the ability of olopatadine $0.2 \%$ to completely prevent ocular itching in adult patients with allergic conjunctivitis, a post-hoc analysis was conducted using the data reported in a previously published, single-center, double-masked, randomized, contralateral eye (ie, patients instilled active study drug in a single eye and vehicle in the fellow eye), CAC study. ${ }^{14}$ The overall results in that study demonstrated the efficacy of olopatadine $0.2 \%$ in reducing ocular itching at onset, as well as at 16 hours after study drug administration $(P<0.001)$. For the purposes of the post-hoc analysis described herein, the evaluation was designed to compare the proportion of contralaterally dosed patients who had no ocular itching in the olopatadine $0.2 \%$-treated eye to the proportion of patients who had no ocular itching in the vehicle-treated eye at three time points following study drug administration (ie, at the onset of action challenge). Using this analysis, an important potential advantage of a multi-action compound (ie, the complete prevention of ocular itching following study drug administration) was investigated relative to a vehicle that would be expected only to wash an offending allergen from the eye.

\section{Patients and methods}

\section{Inclusion and exclusion criteria}

This study included adult patients, 18 years of age and older, who had histories of allergic conjunctivitis, as confirmed by a positive case history and a positive skin test reaction (within the preceding 24 months) to cat hair/dander, ragweed, dust mites, grasses, and/or trees. At both visit 1 (screening) and visit 2 (confirmatory), patients must also have had positive bilateral CAC results (defined by itching scores $\geq 2$ for each eye as graded using a scale ranging from 0 [none] to 4 [incapacitating itch], as well as redness scores $\geq 2$ in one of the three vessel beds for each eye as graded using a scale ranging from 0 [no redness] to 4 [extremely severe redness]; 
half-unit increments were allowed in both scales). Patients must not have had any concurrent diseases or needed the use of concomitant medications that might have interfered with the evaluation of the study medication. While there was no formal washout period, patients must not have used any of the following medications during the study or within 3 days of visit 1: antihistamines, steroids, mast cell stabilizers, nonsteroidal anti-inflammatory agents, intranasal decongestants, topical ocular preparations (including artificial tears), and immunosuppressives. Patients were excluded from the study if they had histories of moderate to severe allergic asthma reactions associated with the test allergens, or if they exhibited ocular itching and/or redness in any of the three vessel beds at the start of any study visit. Finally, all patients were recruited either through advertising or chart review.

\section{Test articles}

Olopatadine $0.2 \%$ and vehicle were supplied in identical, masked containers. A technician who was not involved with the conduct or evaluation of any of the efficacy or safety measurements instilled the study medications into the eyes of each patient. In this manner, the investigators, their study staff, the monitors, and all others involved with the conduct of the study were kept masked in regard to each individual patient's treatment assignment. Patients included in the posthoc analysis were randomly assigned to receive one drop of olopatadine $0.2 \%$ in one eye and one drop of vehicle in the contralateral eye.

\section{Study design}

The study consisted of four visits conducted over a period of 5 weeks: screening (visit 1), confirmatory challenge (visit 2, conducted 7 days after visit 1), duration of action challenge (visit 3, conducted 14 days after visit 2), and onset of action challenge (visit 4, conducted 14 days after visit 3 ).

During visit 1, patients provided informed consent, reported their medical histories and concomitant medication usages, and were evaluated against the inclusion/exclusion criteria. All patients had their visual acuities assessed, and female patients of childbearing potential underwent urine pregnancy tests. Additionally during this visit, a bilateral CAC was performed to determine the concentration of allergen required in each patient to elicit a positive allergic reaction. The severity of ocular itching was evaluated by the patients, whereas the investigator assessed ocular redness independently for each of the individual vessel beds using a standardized set of reference photographs; full descriptions of the ocular itching and conjunctival redness scales, along with representations of the reference images used to evaluate redness, were reported previously. ${ }^{15}$

The combination of the allergen and its concentration used to successfully elicit a positive response from a specific patient at visit 1 was confirmed at visit 2 and then used in the allergen challenge performed for that same patient at every subsequent study visit. Specifically, at visits 3 and 4, the study medications were administered and a bilateral CAC was performed; the allergen challenge occurred 16 hours after study drug administration at visit 3 and 27 minutes after study drug administration at visit 4 . At both visits, patient assessments of ocular itching were conducted prior to study drug administration (baseline) and at 3, 5, and 7 minutes post-challenge. Additionally at each visit, visual acuity and slit-lamp examinations of the cornea, iris/anterior chamber, and lens were conducted prior to study drug instillation and prior to the CAC.

Throughout the study, both elicited and observed adverse events (AEs) were reported. Further, as part of the safety evaluation, patients underwent undilated fundus examinations at visit 1 (pre-CAC) and visit 4 (post-dose, prior to the CAC). Post-CAC visual acuity assessments and slit-lamp examinations were also conducted at visit 4 before each patient completed the study, and female patients of childbearing potential underwent repeat urine pregnancy tests prior to exiting.

The study was conducted in accordance with Good Clinical Practices and the ethical principles described within the Declaration of Helsinki. All participating patients gave written informed consent; the study protocol and the informed consent document were reviewed and approved by an institutional review board (IntegReview, Austin, TX).

\section{Efficacy analysis}

The post-hoc analysis included patients who administered both study formulations contralaterally and who had ocular itching assessments available for both the baseline and allergen challenge at visit 4 (the onset of action challenge); no imputations were made for missing data. The post-hoc efficacy variable was defined as the proportion of patients who, at visit 4 , reported an ocular itching score of 0 (ie, had no ocular itching) in each treated eye (by study medication) at 3 , 5 , and 7 minutes post-CAC. The efficacy analysis then compared the proportion of patients who had no ocular itching in the olopatadine $0.2 \%$-treated eye to the proportion of patients who had no ocular itching in the vehicle-treated eye at each of the three assessment time points; all comparisons were conducted using McNemar's tests with inferences drawn at 
the 0.05 alpha level. Note that, because the objective of the post-hoc analysis was to evaluate the ability of each study medication to completely prevent ocular itching following study drug administration, the analysis was restricted to data collected at visit 4 (ie, CAC data reported 16 hours after study drug administration at visit 3 were not evaluated).

\section{Safety analysis}

Safety was not reevaluated in the post-hoc analysis. Within the previously published report of the full study results, ${ }^{14}$ a review of AEs and outcomes of visual acuity, slit-lamp biomicroscopy, and undilated fundus examinations was presented.

\section{Results}

Between February and April 2002, 46 patients were enrolled and randomly assigned to receive contralateral instillations of olopatadine $0.2 \%$ and vehicle. Overall, 40 patients were included in the post-hoc efficacy analysis, while six patients were excluded as they did not have data present at the onset of action challenge. The study was conducted at a single investigational center in the US.

\section{Demographics}

The demographic characteristics of all patients enrolled in the study were described previously. ${ }^{14}$ Overall, most of the patients were white $(92.4 \%)$, female $(58.7 \%)$, and between the ages of 18 and 64 years $(97.8 \%)$. There were no differences in demographic characteristics between patients who were randomized to the different treatment groups.

\section{Efficacy - proportion of patients reporting itching scores of 0 in each eye}

At each assessment time point following the onset of action challenge, significantly greater proportions of patients reported itching scores of 0 for the eye in which olopatadine $0.2 \%$ was instilled than for the eye in which vehicle was instilled (3 minutes, $63 \%$ versus 3\%, respectively; 5 minutes, $63 \%$ versus $5 \%$, respectively; 7 minutes, $65 \%$ versus $10 \%$, respectively $[P<0.05$ for the comparison of olopatadine $0.2 \%$ to vehicle at each time point]) (Figure 1 ). Thus, the post-hoc efficacy results demonstrate that olopatadine $0.2 \%$ is superior to vehicle in regard to the complete prevention of ocular itching resulting from allergen exposure following study drug administration.

\section{Safety}

Of the 46 patients who received contralaterally dosed study medication, three patients experienced AEs, which included

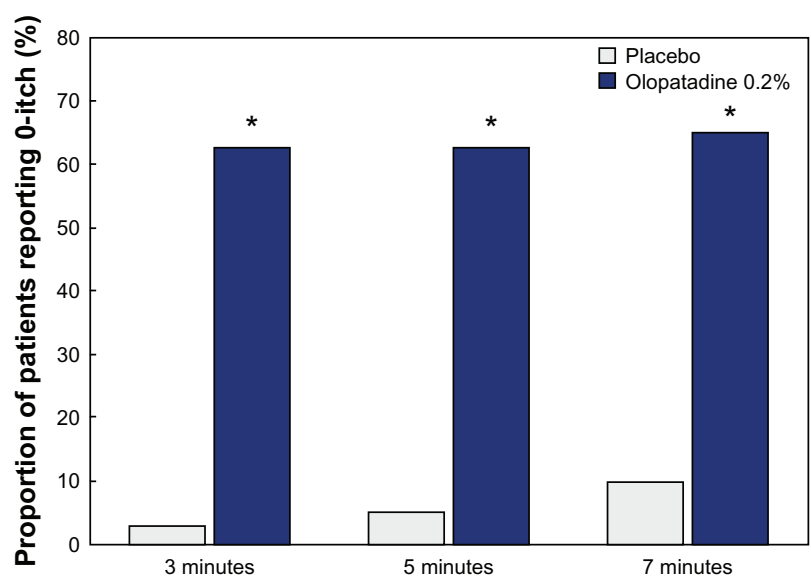

Figure I Proportion of patients reporting itching scores of 0 in each eye following study drug administration.

Notes: *Denotes significant difference between olopatadine $0.2 \%$ and vehicle; $P<0.05$. $P$-values are from McNemar's tests.

itchy and teary eyes (both reported in one patient), mucous (reported in one patient), and sore throat (reported in one patient). None of these events were serious, severe, or treatment-related. In general, there were no clinically relevant changes from baseline in visual acuity, ocular signs, or fundus parameters evaluated during the study.

\section{Discussion}

The purpose of multi-action topical anti-allergic drops is to antagonize histamine $\mathrm{H} 1 / \mathrm{H} 2$ receptor binding, which results in immediate relief of early-phase symptoms (a function of antihistaminic drugs), inhibit mast cell degranulation (a function of mast cell stabilizing drugs), and reduce ocular surface damage through downregulation or inhibition of various inflammatory markers that impact the early and late phases of the conjunctival allergic response. ${ }^{16,17}$

In particular, ocular itching, which is mediated primarily by histamine through interaction with $\mathrm{H} 1$ receptors, is a key characteristic of the allergic response and is a common source of irritation among individuals with allergic conjunctivitis. ${ }^{4,13,14}$ Multi-action anti-allergic compounds, such as olopatadine $0.2 \%$, impact several components of the allergic cascade, are safe for topical ocular use, and have been associated with an extended duration of clinical effect. ${ }^{18}$ Specifically, previous CAC studies have consistently demonstrated the superiority of olopatadine $0.2 \%$ relative to vehicle and other topical ocular antihistamines in the reduction of ocular itching. ${ }^{13,14,19,20}$ Additionally, these studies have collectively indicated that both the antihistaminic and mast cell stabilizing properties of olopatadine $0.2 \%$ extend for at least 16 hours and that olopatadine $0.2 \%$ remains safe and effective throughout the day. 
While the efficacy of olopatadine $0.2 \%$ in the reduction of ocular itching is well documented, patients may not understand the differences between a multi-action compound and over-the-counter artificial tear products. As such, they may self select and self administer a product that provides less than efficacious treatment of ocular itching associated with allergic conjunctivitis. Olopatadine $0.2 \%$, however, is not only capable of reducing ocular itching following study drug administration, but as shown in this report, is also capable of completely preventing the symptom in a substantial proportion of patients who used olopatadine $0.2 \%$ in one eye relative to vehicle in the fellow eye. A recognized limitation of the study is that the CAC model artificially induces an allergic response and is used to evaluate the prevention of that response, whereas in clinical practice, actual symptoms are treated as they occur. It is further acknowledged that there are limitations to a post-hoc analysis, including the possible introduction of bias. The results of the analysis described herein are nevertheless compelling and are based on evaluations conducted in a double-masked, randomized, well controlled clinical study. In particular, the post-hoc analysis shows that $63 \%-65 \%$ of patients (ie, nearly two-thirds) reported itching scores of 0 at the onset of action challenge for the eye in which olopatadine $0.2 \%$ was instilled compared with $3 \%-10 \%$ of patients who reported itching scores of 0 at the same challenge for the eye in which vehicle was instilled. In general, these results suggest that treatment of ocular itching associated with allergic conjunctivitis is highly successful following administration of a topical ocular, multi-action compound, while the use of a nonactive product (like an artificial tear product) may yield substantially less relief.

\section{Conclusion}

The results of this post-hoc analysis demonstrate that olopatadine $0.2 \%$ is superior to vehicle in the complete prevention of ocular itching associated with allergic conjunctivitis $(P<0.05)$. Specifically, the analysis showed that nearly two-thirds of the patients treated with olopatadine $0.2 \%$ experienced a complete prevention of ocular itching following study drug administration compared with no more than $10 \%$ of the patients treated with vehicle. The fact that olopatadine $0.2 \%$ completely prevents ocular itching following instillation, while the vehicle generally does not, yields a novel advantage for this particular multi-action treatment relative to nonprescription alternatives. This finding may be important when educating patients in regard to the differences between some over-the-counter products and prescription medications intended for use in patients with allergic conjunctivitis.

\section{Acknowledgments}

Cullen T Vogelson, $\mathrm{PhD}$, and Usha Sivaprasad, $\mathrm{PhD}$, of Illuminated Research, LLC provided medical writing support, which was funded by Alcon Laboratories, Inc.

\section{Disclosure}

This study was sponsored by Alcon Research, Ltd. Drs Kabat, Granet, and Blaiss are consultants for Alcon. Ms Amin and Dr Tort are Alcon employees. This manuscript was developed from a poster presented at the American Optometric Association Annual Meeting, June 16-20, 2010, Orlando, FL. Some of the data were previously presented in posters (at the Western Society of Allergy, Asthma and Immunology Meeting, January 24-28, 2010 in Maui, HI, and at the International Scientific Conference of the World Allergy Organization, December 5-8, 2010 in Dubai, UAE) and in a manuscript (see Abelson et al ${ }^{14}$ ).

\section{References}

1. Bielory L. Update on ocular allergy treatment. Expert Opin Pharmacother. 2002;3(5):541-553.

2. Ciprandi G, Buscaglia S, Cerqueti PM, Canonica GW. Drug treatment of allergic conjunctivitis. A review of the evidence. Drugs. 1992;43(2): $154-176$.

3. Abelson MB, Smith LM, Chapin M. Ocular allergic disease: mechanisms, disease sub-types, treatment. Ocul Surf. 2003;1(3):127-149.

4. Leonardi A, Quintieri L. Olopatadine: a drug for allergic conjunctivitis targeting the mast cell. Expert Opin Pharmacother. 2010;11(6): 969-981.

5. Leonardi A, De Dominicis C, Motterle L. Immunopathogenesis of ocular allergy: a schematic approach to different clinical entities. Curr Opin Allergy Clin Immunol. 2007;7(5):429-435.

6. Leonardi A, Motterle L, Bortolotti M. Allergy and the eye. Clin Exp Immunol. 2008;153 (Suppl 1):17-21.

7. Pataday ${ }^{\mathrm{TM}}$ [package insert], Fort Worth, TX: Alcon Laboratories, Inc; 2006-2009.

8. Sharif NA, Xu SX, Miller ST, Gamache DA, Yanni JM. Characterization of the ocular antiallergic and antihistaminic effects of olopatadine (AL-4943A), a novel drug for treating ocular allergic diseases. J Pharmacol Exp Ther. 1996;278(3):1252-1261.

9. Berdy GJ, Berdy SS. Ocular allergic disorders: disease entities and differential diagnosis. Curr Allergy Asthma Rep. 2009;9(4):297-303.

10. Bielory L. Allergic diseases of the eye. Med Clin North Am. 2006;90(1): 129-148.

11. Bielory L, Katelaris CH, Lightman S, Naclerio RM. Treating the ocular component of allergic rhinoconjunctivitis and related eye disorders. Med Gen Med. 2007;9(3):35.

12. Abelson MB, Chambers WA, Smith LM. Conjunctival allergen challenge. A clinical approach to studying allergic conjunctivitis. Arch Ophthalmol. 1990;108(1):84-88.

13. Vogelson CT, Abelson MB, Pasquine T, et al. Preclinical and clinical antiallergic effect of olopatadine $0.2 \%$ solution 24 hours after topical ocular administration. Allergy Asthma Proc. 2004;25(1):69-75.

14. Abelson MB, Gomes PJ, Pasquine T, Edwards MR, Gross RD, Robertson SM. Efficacy of olopatadine ophthalmic solution $0.2 \%$ in reducing signs and symptoms of allergic conjunctivitis. Allergy Asthma Proc. 2007;28(4):427-433.

15. Abelson MB. Evaluation of olopatadine, a new ophthalmic antiallergic agent with dual activity, using the conjunctival allergen challenge model. Ann Allergy Asthma Immunol. 1998;81(3):211-218. 
16. Bielory L, Lien KW, Bigelsen S. Efficacy and tolerability of newer antihistamines in the treatment of allergic conjunctivitis. Drugs. 2005; 65(2):215-228.

17. Lambiase A, Micera A, Bonini S. Multiple action agents and the eye: do they really stabilize mast cells? Curr Opin Allergy Clin Immunol. 2009;9(5):454-465.

18. Abelson MB, Torkildsen GL, Williams JI, Gow JA, Gomes PJ, McNamara TR. Time to onset and duration of action of the antihistamine bepotastine besilate ophthalmic solutions $1.0 \%$ and $1.5 \%$ in allergic conjunctivitis: a phase III, single-center, prospective, randomized, double-masked, placebo-controlled, conjunctival allergen challenge assessment in adults and children. Clin Ther. 2009;31(9):1908-1921.
19. Abelson MB, Spangler DL, Epstein AB, Mah FS, Crampton HJ. Efficacy of once-daily olopatadine $0.2 \%$ ophthalmic solution compared to twice-daily olopatadine $0.1 \%$ ophthalmic solution for the treatment of ocular itching induced by conjunctival allergen challenge. Curr Eye Res. 2007;32(12):1017-1022.

20. Mah FS, Rosenwasser LJ, Townsend WD, Greiner JV, Bensch G. Efficacy and comfort of olopatadine $0.2 \%$ versus epinastine $0.05 \%$ ophthalmic solution for treating itching and redness induced by conjunctival allergen challenge. Curr Med Res Opin. 2007;23(6):1445-1452.
Clinical Optometry

\section{Publish your work in this journal}

Clinical Optometry is an international, peer-reviewed, open access journal publishing original research, basic science, clinical and epidemiological studies, reviews and evaluations on clinical optometry. All aspects of patient care are addressed within the journal as well as the practice of optometry including economic and business analyses. Basic and clinical

\section{Dovepress}

research papers are published that cover all aspects of optics, refraction and its application to the theory and practice of optometry. The manuscript management system is completely online and includes a very quick and fair peer-review system, which is all easy to use. Visit http://www.dovepress. com/testimonials.php to read real quotes from published authors. 